\title{
Distribution of intraperitoneally injected diclofenac in brown trout (Salmo trutta f. fario) ${ }^{\text {is }}$
}

\author{
Birgit Hoeger ${ }^{\mathrm{a}, 1}$, Daniel R. Dietrich ${ }^{\mathrm{a}}$, Daniela Schmid ${ }^{\mathrm{a}, 2}$, Andreas Hartmann ${ }^{\mathrm{b}}$, \\ Bettina Hitzfeld ${ }^{\mathrm{c}, *}$ \\ ${ }^{a}$ Human and Environmental Toxicology, University of Konstanz, 78464 Konstanz, Germany \\ ${ }^{\mathrm{b}}$ Novartis Pharma AG, Technical Operations, HSE and BC, 4058 Basel, Switzerland \\ ${ }^{\mathrm{c}}$ Federal Office for the Environment (FOEN), Substances, Soil and Biotechnology Division, 3003 Berne, Switzerland
}

\begin{abstract}
The detection of low levels of pharmaceuticals in aquatic environments has lately raised concerns regarding possible adverse effects of these highly active substances on aquatic organisms. The non steroidal anti inflammatory drug diclofenac (DCF) is one of the pharmaceutical substances regularly detected in surface waters and has lately been demonstrated to elicit adverse effects in salmonid species at environmentally relevant concentrations. The aim of the present study was to investigate the distribution of DCF in indigenous brown trout (Salmo trutta f. fario) following intraperitoneal (i.p.) injection of a single dose of ${ }^{14} \mathrm{C}$ labelled DCF. A distribution kinetic over $36 \mathrm{~h}$ provides information on possible accumulation of DCF in different organs as well as on DCF detoxification in trout, possibly enabling identification of sites of preferential toxicity. Approximately $57 \%$ of the total single DCF dose appeared in the bile $6 \mathrm{~h}$ after i.p. application. Subsequently, DCF was observed to undergo enterohepatic cycling with an amount of ${ }^{14} \mathrm{C}$ activity comparable to the $6 \mathrm{~h}$ bile values reappearing in bile $36 \mathrm{~h}$ after application. Results for ${ }^{14} \mathrm{C}$ activity in intestine and pylori support the observation of enterohepatic cycling with a small peak in intestine at $3 \mathrm{~h}$ post i.p. injection and a low peak in intestine and pylori at $6 \mathrm{~h}$ post i.p. injection, reflecting presence of the drug substance in bile. The highest activity in intestine was found $24 \mathrm{~h}$ post injection coinciding with low levels in bile, followed by a gradual decrease of activity in intestine mirroring the re uptake of DCF into bile. The finding of enterohepatic cycling of DCF in brown trout is suggestive of a prolonged retention of DCF in brown trout.
\end{abstract}

Keywords: Diclofenac; NSAID; Brown trout; Salmo trutta; Pharmaceuticals in the environment

\section{Introduction}

In recent years residues of human pharmaceuticals have been detected in various aquatic environments (Dietrich et al., 2004, 2006). The almost ubiquitous occurrence and

\footnotetext{
The study was conducted according to the guideline for the protection of animal welfare by and under permit of the Land Baden Wurttemberg, Germany.

*Corresponding author. Fax: +41313247978.

E mail addresses: birgit.hoeger@novartis.com (B. Hoeger), bettina.hitzfeld@bafu.admin.ch (B. Hitzfeld).

${ }^{1}$ Present address: Novartis Pharma AG, Technical Operations, HSE and BC, 4058 Basel, Switzerland.

${ }^{2}$ Present address: Department of Bioorganic Chemistry, MPI for Chemical Ecology, Germany.
}

constant input of certain pharmaceuticals through sewage treatment effluents has ever since been thought to result in a chronic low-level exposure of aquatic organisms. As pharmaceuticals are designed to specifically interact with biochemical mechanisms of a higher vertebrate species at low concentrations, adverse effects on non-target species may be possible in spite of the generally low toxicity of these compounds in mammalian species and the low levels found in the environment. As fish possess a wide range of phylogenetically highly conserved receptors, transporters, enzymes (e.g. cyclooxygenases (COX); Zou et al., 2000; Grosser et al., 2002), peptides and proteins, i.e. constituents of those biochemical mechanisms or signal-transduction pathways specifically targeted in the human as a means of medical treatment (Rowley et al., 1995; Zou et al., 2000), 
fish populations chronically exposed to low concentrations of these pharmaceuticals may be adversely affected.

One of the human pharmaceuticals regularly found in surface waters is the non-steroidal anti-inflammatory drug (NSAID) diclofenac (DCF), which is predominantly used to treat rheumatic diseases and inflammations of the musculoskeletal system (Buser et al., 1998). The mode of action of DCF is threefold: inhibition of COX and lipoxygenases as well as reduction of the level of free arachidonic acid. The inhibition of COX in mammalian species leads to a change in prostaglandin levels with a concomitant reduction of the inflammatory response and pain as well as a suppression of blood coagulation and a reduction of kidney activity. DCF has previously been shown to adversely affect various tissues in patients, including the gastro-intestinal tract, the liver and the kidney (Atchison et al., 2000; Banks et al., 1995; Hickey et al., 2001). Recently, adverse effects of DCF, such as accumulation of protein droplets in the kidney and gill pathology have been reported in rainbow trout (Oncorhynchus mykiss) (Schwaiger et al., 2004; Triebskorn et al., 2004) and brown trout (Hoeger et al., 2005) following sub-acute to sub-chronic exposure.

In patients as well as in rats DCF has been shown to undergo extensive enterohepatic circulation and is thus not entirely excreted after first-pass metabolism (Fukuyama et al., 1994; Reuter et al., 1997). In humans the primary metabolite resulting from phase II metabolism is suggested to be a DCF-glucuronide conjugate (Seitz and Boelsterli, 1998). Excretion of DCF in humans is thought to occur via the bile and the kidney at $35 \%$ and $65 \%$, respectively. Renal toxicity in humans and rodents primarily appears to occur following acute or sub-chronic exposure to very high doses of DCF. A possible mode of action for nephrotoxicity observed in mammalian species is through the reaction of $\mathrm{DCF}$-glucuronide with tissue proteins leading to $\mathrm{DCF}-\mathrm{glu}-$ curonide protein adducts, as previously identified in liver. The question was raised whether the renal pathology observed in trout following sub-chronic exposure to very low concentrations of DCF has an identical underlying mechanism. Therefore, the aim of the present study was to investigate the distribution of DCF in the indigenous brown trout (Salmo trutta f. fario) following intraperitoneal (i.p.) injection of a single dose. Albeit not at an environmentally relevant concentration and exposure route, a distribution kinetic over $36 \mathrm{~h}$ post-application should provide information on sites (organs) of DCF accumulation and/or possible detoxification. Thus, sites of preferential toxicity could possibly be identified. Additional studies on possible conjugates of DCF formed in brown trout should further provide understanding of DCF metabolism and the underlying excretion pathways in salmonid species.

\section{Material and methods}

\subsection{Distribution kinetics with ${ }^{14}$ C labelled DCF}

One year old brown trout ( $S$. trutta f. fario) were purchased from the hatchery Peter Stoerk (Bad Saulgau, Germany). Body weight and fork
Table 1

Physico chemical properties of diclofenac

\begin{tabular}{lcl}
\hline Parameter & Value & Reference \\
\hline $\log K_{\text {ow }}$ & 1.56 & Novartis MSDS \\
$\log D$ & 1.22 & Barbato et al. (1997) \\
$\mathrm{p} K_{\mathrm{a}}$ & 3.90 & \\
Water solubility (g/l) & 21.3 & Novartis MSDS \\
Structural formula &
\end{tabular}

length of trout used for the experiment were $51.09 \pm 10.2 \mathrm{~g}$ and $15.9 \pm 1.18 \mathrm{~cm}$, respectively. Eighteen trout were injected intraperitoneally with $6.15 \mu \mathrm{g}(70.45 \mathrm{kBq}){ }^{14} \mathrm{C}$ labelled DCF ([2 (2,6 dichloro phenylami no) $\left[\mathrm{U}^{14} \mathrm{C}\right]$ phenyl] acetic acid sodium salt) (kindly provided by Novartis Pharma AG, Basel, Switzerland; see also Table 1), in $0.9 \%$ saline, each (the study was conducted according to the guideline for the protection of animal welfare by and under permit of the Land Baden Wurttemberg, Germany). The initial ${ }^{14} \mathrm{C}$ DCF dose was determined based on assump tions on probable recovery rates $(60 \%)$ in organ samples and detection limits for ${ }^{14} \mathrm{C}$ liquid scintillation counting. Individual trout were kept in separate 151 tap water aquaria. Exposure durations were $45 \mathrm{~min}, 3,6,12$, 24 , and $36 \mathrm{~h}$. Water temperature up to $6 \mathrm{~h}$ exposure was $16^{\circ} \mathrm{C}$ and in the longer exposure times up to $19^{\circ} \mathrm{C}$. Additional aeration was provided throughout all exposure durations. Three trout were killed at each time point and the DCF distribution analysed. Water samples were taken regularly to monitor excretion of DCF, i.e. every 5 min during the $45 \mathrm{~min}$ exposures and every $15 \mathrm{~min}$ during the $3 \mathrm{~h}$ exposures and throughout the first hour of the longer exposure experiments. In the $6 \mathrm{~h}$ experiments, beyond the first hour, water samples were taken every $30 \mathrm{~min}$ while in the $1236 \mathrm{~h}$ exposure samples were taken every $30 \mathrm{~min}$ in the second hour followed by sampling every hour for the rest of the experiments with a $6 \mathrm{~h}$ break during the night in the 24 and $36 \mathrm{~h}$ exposures. At termination of exposure, trout were anaesthetized with ethyl 3 aminobenzoate methane sulfonate (MS 222) (Fluka, Buchs, Switzerland). Blood samples were taken from the caudal vein and $30 \mu \mathrm{l}$ blood pipetted into a $10 \mathrm{ml}$ scintillation vial and weighed. Half of the head kidney, trunk kidney and spleen, gills from one side of the fish, separated from their gill arches, and parts of stomach, pylorus, intestine, liver, and muscle weighing between 100 and $300 \mathrm{mg}$ were snap frozen using liquid nitrogen and then transferred into scintillation vials and weighed. Remaining organ tissue was transferred into cryo vials, weighed, snap frozen using liquid nitrogen and stored at $80^{\circ} \mathrm{C}$. One millimetre NCS II tissue solubilizer (Amersham Biosciences, Little Chalfont, UK) was added per sample. After digestion of samples for $48 \mathrm{~h}, 100 \mu \mathrm{l}$ acetic acid and $3 \mathrm{ml}$ scintillation cocktail for organic samples (BCS NA counting scintillant; Amersham Biosciences) were added and ${ }^{14} \mathrm{C}$ activity was measured as decays per minute (dpm) (LS 6500 multi purpose scintillation counter; Beckman Coulter Inc., Fullerton, USA). Water samples were mixed with acetic acid and scintillation cocktail for aqueous samples (Ready Safe; Beckman Coulter Inc.) prior to counting. ${ }^{14} \mathrm{C}$ activity in Becquerel $(\mathrm{Bq})$ was calculated by dividing dpm by the factor 60 . The whole experiment was conducted in duplicate. As the results from the two duplicate experiments were comparable, only the results of the second experiment, considered representative of both duplicate experiments, are shown in a figure. Indeed, the combination of both duplicate experiments in one dataset would have increased 
the variability at each time point and therefore resulted in a loss of information.

DCF recovery in the different organs is expressed as percent of total ${ }^{14} \mathrm{C}$ activity determined in the whole animal. While total organ weights could be measured for liver, spleen, head kidney, trunk kidney, stomach, pylorus, and intestine, blood volume and muscle weight was determined theoretically via the assumption that a fish has $3.5 \mathrm{ml}$ blood/100 $\mathrm{g}$ body weight (Itazawa et al., 1983; Tort et al., 1991) and muscle tissue represents approximately $60 \%$ of the body weight.

\subsection{Thin layer chromatography (TLC) for the detection of $D C F$ phase II conjugation}

Two brown trout (age 1 year) were injected i.p. with $6.15 \mu \mathrm{g}(70.45 \mathrm{kBq})$ ${ }^{14} \mathrm{C}$ DCF in $0.9 \%$ saline and kept separately in aquaria. Following $6 \mathrm{~h}$ exposure, tissue samples were dissected, snap frozen, and kept at $80^{\circ} \mathrm{C}$ pending further analysis. TLC on an aluminium sheet with silica gel 60 $\mathrm{F}_{254}$ (Merck KGaA, Darmstadt, Germany) was carried out with the following samples: (1) bile from an untreated trout as control; (2) bile from an untreated trout spiked with ${ }^{14} \mathrm{C}$ DCF stock solution, resulting in an activity of $40 \mathrm{kBq}$; (3) bile of a ${ }^{14} \mathrm{C}$ DCF injected trout; (4) ${ }^{14} \mathrm{C}$ DCF stock solution $(40 \mathrm{kBq})$; and (5) bile of a ${ }^{14} \mathrm{C}$ DCF injected trout incubated for $1 \mathrm{~h}$ with 25 units Escherichia coli $\beta$ glucuronidase (Sigma, Steinheim, Germany). Chromatography was performed in a pre equilibrated TLC chamber with a mixture of dichloromethane, methanol (8.5:1.4 parts), and $0.25 \%$ ammonia. After $90 \mathrm{~min}$, the TLC plate was dried and incubated with a phosphor imager plate for $60 \mathrm{~h}$, followed by ${ }^{14} \mathrm{C}$ phosphor imager detection.

\section{Results}

\subsection{Distribution kinetics of ${ }^{14} C$-labelled DCF}

Within $36 \mathrm{~h}$ post i.p. injection of ${ }^{14} \mathrm{C}$-labelled $\mathrm{DCF}$, brown trout excreted approximately half of the applied dose into the ambient water (Fig. 1). The time-excretion data of the individual fish followed a nearly sigmoidal curve with the steepest portion, representing the highest excretion rate $(\mathrm{Bq} / \mathrm{min})$ in the $12-24 \mathrm{~h}$ time period post i.p. and another slight increase in excretion $32 \mathrm{~h}$ post i.p. (Fig. 1). ${ }^{14} \mathrm{C}$-activity in blood and in highly perfused organs (muscle, spleen, kidney, gills, and liver) was the highest at $1 \mathrm{~h}$ post i.p. and then rapidly decreased to near control values at $12 \mathrm{~h}$ post i.p. (Fig. $2 \mathrm{a}$ and b). A slight increase in muscle ${ }^{14} \mathrm{C}$-activity was observable after $12 \mathrm{~h}$ post i.p. injection, peaking at $24 \mathrm{~h}$ and then declining again at $36 \mathrm{~h}$ post i.p. to attain comparable values as already observed at $12 \mathrm{~h}$ (Fig. 2a). A similar curve was observable for ${ }^{14} \mathrm{C}$-activity in the blood although the total activity was much lower than that observed in the muscle. Total ${ }^{14} \mathrm{C}$-activity in spleen, gills, stomach, and kidney was extremely low when compared to total ${ }^{14} \mathrm{C}$-activity detected in bile, intestine, pylorus, muscle, liver, and blood (Table 2). Contrary to the findings for most other organs, ${ }^{14} \mathrm{C}$-activity in the bile quickly rose after $1 \mathrm{~h}$ post i.p. to reach a first peak at $6 \mathrm{~h}$, then gradually declining to a low value at $24 \mathrm{~h}$ post i.p. and then to rise again at $36 \mathrm{~h}$ post i.p. to comparable total ${ }^{14} \mathrm{C}$-activity values as observed at the $6 \mathrm{~h}$ time-point (Fig. 2b). ${ }^{14} \mathrm{C}$-activity in the intestine resulted in a small peak at $3 \mathrm{~h}$ post i.p. with a low point at $6 \mathrm{~h}$ post i.p. and then followed by the highest activity at

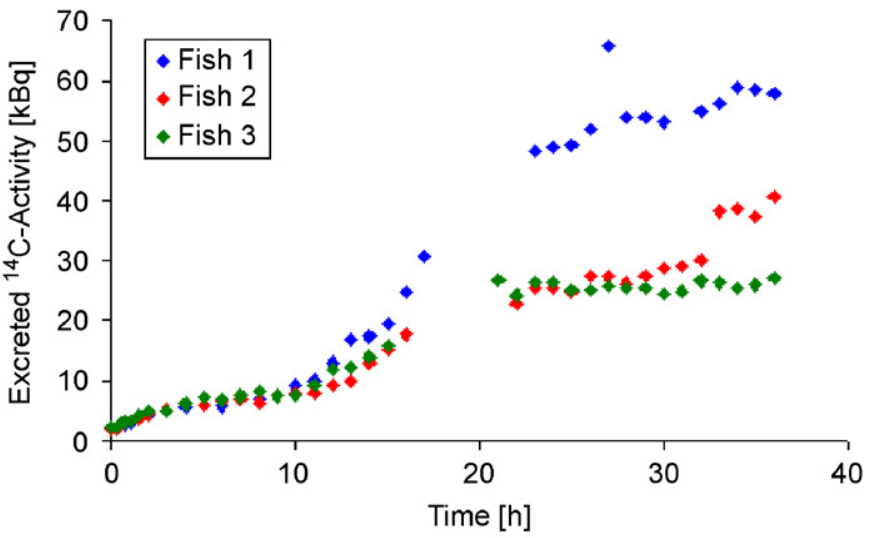

Fig. $1 .{ }^{14} \mathrm{C}$ activity excreted into the surrounding water over a time course of $36 \mathrm{~h}$ after a single i.p. injection of ${ }^{14} \mathrm{C}$ labelled diclofenac. Shown are single measurements from the three brown trout (Salmo trutta f. fario) kept for $36 \mathrm{~h}$.

$24 \mathrm{~h}$ post i.p. (Fig. 2b). The activity curve in the pylori was comparable to the one observed in the intestine, although no early peak was observed. Both, the pyloric and intestinal ${ }^{14} \mathrm{C}$-activity had a maximum peak at $24 \mathrm{~h}$ post i.p. and then gradually declined toward the $36 \mathrm{~h}$ post i.p. time-point. The amount of ${ }^{14} \mathrm{C}$-activity found in the bile $6 \mathrm{~h}$ post i.p. application represented $57 \pm 9.89 \%$ of the total dose applied to the fish.

Full datasets of both experiments are shown in Table 2, given as recovered radioactivity in percent of initial dose.

\subsection{Analysis of DCF-conjugates in bile by TLC}

TLC with bile samples of brown trout, treated with a single dose of ${ }^{14} \mathrm{C}$-labelled DCF, suggested the presence of DCF conjugates (Fig. 3c), which display lower migratory capability than DCF alone (d) or DCF mixed with bile (b). In order to investigate the type of conjugation, bile from a ${ }^{14} \mathrm{C}$-DCF-injected trout was incubated with $\beta$-glucuronidase (Fig. 3e). This incubation resulted in the disappearance of the non-migrating, (presumably conjugated) DCF spot. However, this sample also showed only a relatively small DCF spot with the migratory capability of free DCF.

\section{Discussion}

DCF is an NSAID, which can nowadays be found almost ubiquitously and persistently in the aquatic environment due to its extensive use and excretion of its metabolites as well as un-metabolized compound by patients. The present study revealed that the NSAID DCF undergoes first-pass metabolism in brown trout and accumulates to a considerable amount (approximately $50 \%$ ) in bile during the first $6 \mathrm{~h}$ after i.p. application of a single dose. The most prominent finding of the study at hand, however, is that DCF undergoes enterohepatic cycling, whereby a first re-uptake of DCF into bile was observed within a time frame of $36 \mathrm{~h}$ after i.p. application. Even though employing a higher than environmentally 
a

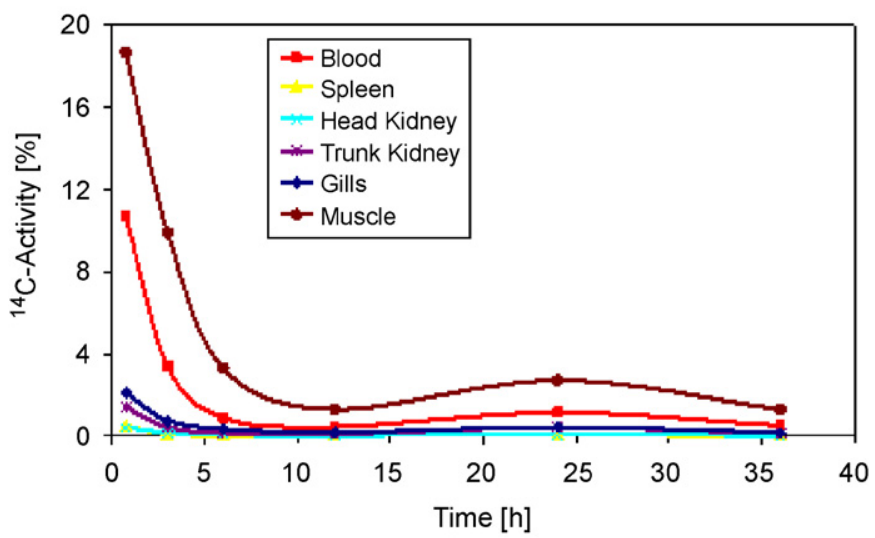

b

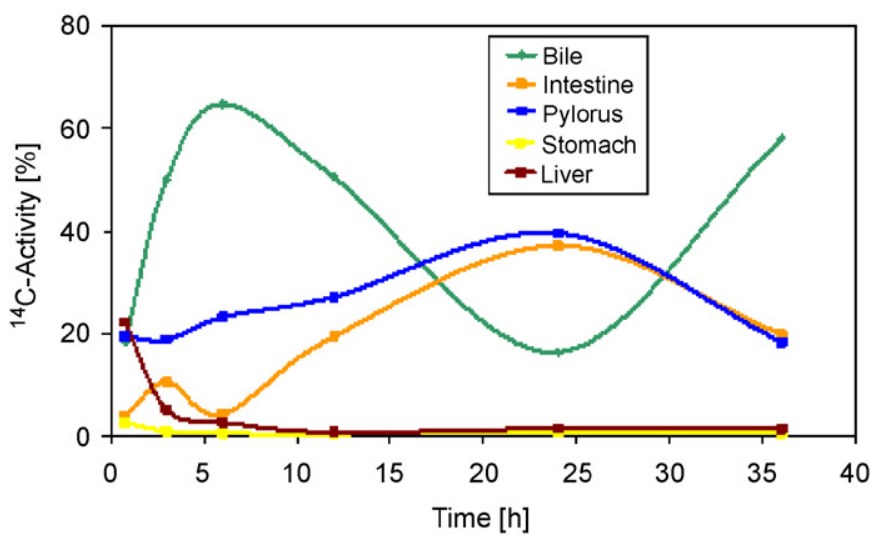

Fig. 2. Distribution kinetics of ${ }^{14} \mathrm{C}$ diclofenac in organs of brown trout (Salmo trutta f. fario) over a time course of $36 \mathrm{~h}$, after a single i.p. injection. Values for the respective organs are calculated as percent ${ }^{14} \mathrm{C}$ activity of the total amount recovered in the organism. Shown are average values of three fish $(n=3)$, representing data from the second experiment. (a) Blood, spleen, head kidney, trunk kidney, gills, and muscle; (b) bile, intestine, pylorus, stomach, and liver. Variability of data is presented in Table 2, providing the full datasets of both replicate experiments.

relevant exposure concentration $(6.15 \mu \mathrm{g}$ per fish, approximately $0.42 \mu \mathrm{g} / \mathrm{l}$, i.e. approximately $4-100$-fold higher than observed in environmental samples) and an artificial exposure pathway (i.p.), the present study does provide interesting insights into the metabolism of DCF in a salmonid species.

The prominent increase of ${ }^{14} \mathrm{C}$-activity in the surrounding water between 12 and $24 \mathrm{~h}$ coincides with a decrease of ${ }^{14} \mathrm{C}$-activity in the bile and might therefore be the result of active excretion of ${ }^{14} \mathrm{C}$-labelled DCF with the bile via faeces. However, with the methodology applied in the present study, it was not possible to clarify, which pathway is the predominant one in the excretion of DCF. Potential pathways for excretion of DCF in fish are via the gills, via faeces, and via urine. The apparent absence of excretion of ${ }^{14} \mathrm{C}$-labelled DCF post- $24 \mathrm{~h}$, coincides with a re-uptake of ${ }^{14} \mathrm{C}-\mathrm{DCF}$ (within the organism) into the bile.

Additional to the assumed enterohepatic cycling, reuptake of DCF into the bile post- $24 \mathrm{~h}$ might also be partially due to re-uptake of unchanged DCF from the ambient water. Huggett et al. (2003) recently described a model to estimate the uptake of pharmaceuticals from the water phase and subsequent steady-state concentrations in plasma based on the hydrophobicity of a substance. Using the equation previously described by Fitzsimmons et al. (2001) for partitioning of a substance between the aqueous phase and arterial blood in trout and a $\log D$ value for DCF of 1.22, a logarithmic coefficient for passive blood/ water partitioning of DCF $\left(\log P_{\mathrm{BW}}\right)$ of $0.0106\left(P_{\mathrm{BW}}\right.$ of 1.0247) can be calculated. The worst-case DCF water concentration in the experimental setup presented here, is approximately $0.21 \mu \mathrm{g} / 1$ (half of the initially injected $6.15 \mu \mathrm{g}$ in 151 of water). Multiplication of this estimated environmental DCF concentration with the above calculated $P_{\mathrm{BW}}$ results in a fish steady state plasma concentration of $0.26 \mu \mathrm{g} / 1 \mathrm{due}$ to (re)-uptake from the water phase (Huggett et al., 2003). Therefore, possible DCF re-uptake from the surrounding water is assumed to be negligible and thus add little to the prolonged exposure of organs/tissues to DCF observed in the single exposure experiment presented here.

An additional slight increase of ${ }^{14} \mathrm{C}$-activity in the ambient water was observed after approximately $32 \mathrm{~h}$ and therefore could represent the result of another cycle of DCF excretion via bile and faeces and concurrent DCF loss from the pilori and intestine (Fig. 2). However, this presumed renewed excretion cycle of ${ }^{14} \mathrm{C}$-activity from the bile was not detectable within the scope of this experiment, as bile DCF uptake and excretion was not determined separately.

The findings that DCF undergoes enterohepatic cycling is in line with observations in mammalian species, including rats and humans (Reuter et al., 1997). DCF sodium salt basically has a relatively low tendency to accumulate in tissues. However, the prolonged availability of DCF, resulting from an incomplete first-pass metabolism mediated excretion, possibly results in a higher DCF accumulation rate than would be expected from the low octanol/water distribution coefficient $(\log D)$ of its sodium salt of 1.22. Enterohepatic cycling has previously been considered to play a major role in DCF toxicity demonstrated in studies with rats, specifically concerning gastrointestinal damage (Beck et al., 1990; Reuter et al., 1997). Target tissues for DCF toxicity as previously described for patients and in studies with rats are intestine, liver and kidney. Especially, in intestine and liver enterohepatic cycling results in repeated/prolonged exposure to the active compound and may thus aggravate toxicity in these organs.

Analysis of bile samples with thin-layer chromatography was applied to demonstrate the presence of conjugated DCF in bile resulting from liver phase II metabolism and possibly help to identify the type of conjugation, which was initially considered to be glucuronidation (Seitz and Boelsterli, 1998). TLC analysis of brown trout bile suggests that DCF occurs, at least partially, in a conjugated form which displays decreased migrating ability (possibly a glucuronide-conjugate, as suggested by the disappearance 
Table 2

${ }^{14} \mathrm{C}$ activity in organs of three separate fish and surrounding water per sampling time point, given as percent values of initial dose

\begin{tabular}{|c|c|c|c|c|c|c|c|c|c|c|c|c|c|c|c|c|c|c|}
\hline & \multicolumn{3}{|c|}{$45 \min$} & \multicolumn{3}{|l|}{$3 \mathrm{~h}$} & \multicolumn{3}{|l|}{$6 \mathrm{~h}$} & \multicolumn{3}{|l|}{$12 \mathrm{~h}$} & \multicolumn{3}{|l|}{$24 \mathrm{~h}$} & \multicolumn{3}{|l|}{$36 \mathrm{~h}$} \\
\hline & Fish 1 & Fish 2 & Fish 3 & & & & & & & & & & & & & & & \\
\hline \multicolumn{19}{|c|}{ (a) Replicate experiment 1} \\
\hline Water & n.d. & n.d. & n.d. & 10.44 & 45.81 & 4.31 & n.a. & 6.53 & 4.63 & 18.70 & 11.90 & 10.04 & 65.37 & 85.80 & 56.26 & 32.55 & 49.82 & 71.46 \\
\hline Blood & n.d. & n.d. & n.d. & 0.31 & 0.12 & 0.16 & 0.05 & 0.05 & 0.06 & 0.04 & 0.03 & 0.04 & 0.01 & 0.01 & 0.00 & 0.01 & 0.01 & 0.01 \\
\hline Spleen & n.d. & n.d. & n.d. & 0.07 & 0.16 & 0.12 & 0.04 & 0.03 & 0.02 & 0.03 & 0.01 & 0.02 & 0.00 & 0.01 & 0.00 & 0.00 & 0.04 & 0.00 \\
\hline Bile & n.d. & n.d. & n.d. & 36.08 & 15.49 & 33.38 & 34.29 & 56.14 & 66.35 & 1.16 & 44.91 & 55.46 & 0.76 & 1.92 & 3.14 & 39.99 & 5.25 & 16.07 \\
\hline Liver & n.d. & n.d. & n.d. & 6.00 & 2.71 & 1.66 & 2.85 & 1.34 & 1.59 & 0.84 & 0.48 & 0.97 & 0.06 & 0.16 & 0.09 & 0.13 & 1.37 & 0.20 \\
\hline Head kidney & n.d. & n.d. & n.d. & 0.19 & 0.06 & 0.07 & 0.04 & 0.05 & 0.06 & 0.03 & 0.02 & 0.02 & 0.01 & 0.02 & 0.01 & 0.01 & 0.01 & 0.02 \\
\hline Trunk kidney & n.d. & n.d. & n.d. & 0.28 & 0.17 & 0.16 & 0.12 & 0.13 & 0.16 & 0.08 & 0.05 & 0.07 & 0.02 & 0.04 & 0.01 & 0.02 & 0.02 & 0.08 \\
\hline Gills & n.d. & n.d. & n.d. & 0.51 & 0.10 & 0.23 & 0.17 & 0.24 & 0.27 & 0.13 & 0.08 & 0.14 & 0.04 & 0.08 & 0.04 & 0.04 & 0.09 & 0.03 \\
\hline Muscle & n.d. & n.d. & n.d. & 8.79 & 4.81 & 8.96 & 2.03 & 2.12 & 2.85 & 2.14 & 0.81 & 0.95 & 0.44 & 0.94 & 0.37 & 0.35 & 0.40 & 0.83 \\
\hline Stomach & n.d. & n.d. & n.d. & 1.60 & 1.18 & 0.67 & 0.37 & 1.46 & 0.72 & 5.01 & 0.28 & 0.69 & 0.06 & 0.14 & 0.02 & 0.04 & 2.05 & 0.12 \\
\hline Pylorus & n.d. & n.d. & n.d. & 11.78 & 6.45 & 8.78 & 4.29 & 1.80 & 5.99 & 18.25 & 3.50 & 2.73 & 2.51 & 2.71 & 3.52 & 2.26 & 13.54 & 1.67 \\
\hline Intestine & n.d. & n.d. & n.d. & 1.89 & 2.12 & 4.39 & 0.94 & 3.19 & 1.95 & 7.72 & 3.68 & 5.30 & 7.86 & 8.38 & 2.78 & 5.54 & 2.61 & 0.17 \\
\hline \multicolumn{19}{|c|}{ (b) Replicate experiment 2} \\
\hline Water & 2.47 & 1.07 & 0.20 & 4.42 & 10.22 & 17.76 & 7.71 & 7.33 & 11.50 & 14.52 & 20.56 & 18.36 & 86.02 & 76.39 & 69.05 & 76.50 & 52.74 & 34.21 \\
\hline Blood & 6.04 & 7.91 & 9.19 & 2.94 & 3.13 & 0.85 & 0.86 & 0.84 & 0.70 & 0.42 & 0.24 & 0.17 & 0.13 & 0.12 & 0.21 & 0.10 & 0.17 & 0.14 \\
\hline Spleen & 0.35 & 0.41 & 0.34 & 0.06 & 0.06 & 0.07 & 0.04 & 0.02 & 0.03 & 0.03 & 0.01 & 0.01 & 0.01 & 0.01 & 0.01 & 0.00 & 0.01 & 0.00 \\
\hline Bile & 15.31 & 9.47 & 14.91 & 42.14 & 31.95 & 26.26 & 64.52 & 46.32 & 62.11 & 1.33 & 48.29 & 60.04 & 0.92 & 2.93 & 3.38 & 11.99 & 5.04 & 40.14 \\
\hline Liver & 17.06 & 14.88 & 15.73 & 2.49 & 6.48 & 1.11 & 2.02 & 3.24 & 1.59 & 0.41 & 0.29 & 0.39 & 0.10 & 0.20 & 0.30 & 0.10 & 0.20 & 1.13 \\
\hline Head kidney & 0.32 & 0.19 & 0.45 & 0.14 & 0.17 & 0.06 & 0.07 & 0.05 & 0.05 & 0.03 & 0.01 & 0.01 & 0.01 & 0.01 & 0.01 & 0.01 & 0.01 & 0.01 \\
\hline Trunk kidney & 0.90 & 1.09 & 1.03 & 0.43 & 0.38 & 0.12 & 0.15 & 0.15 & 0.12 & 0.07 & 0.06 & 0.04 & 0.03 & 0.11 & 0.03 & 0.02 & 0.06 & 0.02 \\
\hline Gills & 1.20 & 1.57 & 1.79 & 0.40 & 0.80 & 0.34 & 0.39 & 0.32 & 0.28 & 0.16 & 0.09 & 0.06 & 0.05 & 0.05 & 0.08 & 0.03 & 0.06 & 0.05 \\
\hline Muscle & 10.06 & 13.22 & 17.15 & 7.99 & 8.76 & 3.27 & 3.50 & 2.88 & 2.49 & 1.16 & 0.75 & 0.42 & 0.28 & 0.39 & 0.43 & 0.23 & 0.49 & 0.19 \\
\hline Stomach & 1.90 & 1.27 & 2.18 & 0.66 & 0.78 & 0.31 & 0.43 & 0.35 & 0.27 & 0.21 & 0.15 & 0.22 & 0.05 & 0.10 & 0.13 & 0.03 & 0.06 & 0.34 \\
\hline Pylorus & 14.47 & 14.21 & 12.89 & 11.08 & 10.63 & 15.04 & 21.56 & 22.53 & 17.28 & 29.19 & 9.60 & 7.94 & 3.05 & 5.26 & 8.62 & 1.47 & 9.59 & 2.22 \\
\hline Intestine & 3.27 & 2.20 & 2.42 & 4.41 & 2.21 & 13.38 & 1.90 & 7.27 & 1.67 & 18.14 & 9.55 & 6.81 & 3.76 & 6.23 & 4.67 & 2.65 & 7.38 & 5.76 \\
\hline
\end{tabular}

n.d. $=$ not determined.

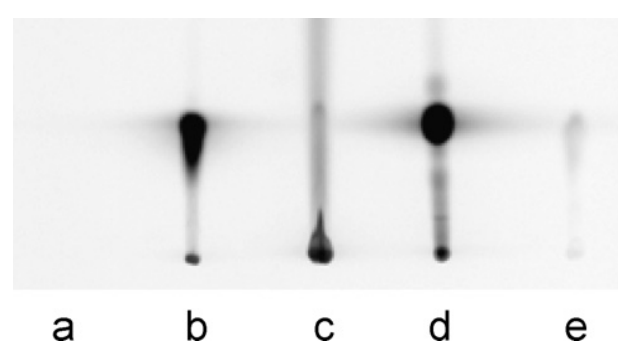

Fig. 3. Thin layer chromatography with bile samples of ${ }^{14} \mathrm{C}$ diclofenac injected brown trout (Salmo trutta f. fario): (a) bile of an untreated trout, (b) bile of an untreated trout complemented with ${ }^{14} \mathrm{C}$ diclofenac, (c) bile of a ${ }^{14} \mathrm{C}$ diclofenac injected trout, (d) ${ }^{14} \mathrm{C}$ diclofenac standard solution, and (e) bile of a ${ }^{14} \mathrm{C}$ diclofenac injected trout, after incubation with $\beta$ glucuronidase.

of this spot after $\beta$-glucuronidase treatment). However, the experiment did not allow unequivocal identification of all possible types of phase II metabolites, as e.g. possible DCF-glutathion conjugates could display faster migrating properties than parent DCF and therefore may no longer be detected with the TLC analysis applied in this study. Grillo et al. (2003a,b) assumed that in rats DCF is conjugated with glucuronide in the course of phase II metabolism. However, as the resulting DCF-glucuronide conjugate remains reactive the glucuronide is subsequently substituted by glutathion. Boelsterli (2003) also described the occurrence of DCF acyl-glucuronids in humans and experimental animals, which remain reactive and can lead to protein adducts unless scavenged by glutathion. In trout, DCF is possibly also partially excreted as reactive DCF acyl-glucuronide via the kidney, where it could provide for protein adducts, as has been described previously in the liver where these adducts are considered causal in the observed idiosyncratic hepatotoxicity (Kretz-Rommel and Boelsterli, 1994; Hargus et al., 1994, 1995). The formation of DCF-protein adducts may also be responsible for kidney pathology described for DCF exposed humans and fish (Hickey et al., 2001; Oaks et al., 2004; Risebrough, 2004; Schwaiger et al., 2004).

At present the toxicological mechanisms underlying adverse effects of DCF observed in liver and kidney have not been clearly elucidated. The observation of inflammatory reactions in these organs, e.g. reflected in monocyte infiltration in liver and increased granulocyte numbers and MHC II expression in kidney (Hoeger et al., 2005), however, may be indicative of a hypersensitivity reaction against DCF-protein adducts. Alternatively, adverse effects, especially in kidney may result from suppression of cyclooxygenase activity, correspondingly lower prostaglandin levels and consequently the deregulation of ion balances (Sanchez et al., 2002). Disturbance of ion balance in turn can impede kidney function, e.g. followed 
by incomplete excretion, which can result in increased inflammation and kidney pathology. Irrespective of the underlying toxicological mechanism, the prolonged/repeated exposure to DCF due to enterohepatic cycling may potentially aggravate adverse effects in some organs in fish, similar to what has been observed in rodents.

In conclusion, the present study demonstrated that DCF is not completely excreted through first pass metabolism in brown trout, but that a significant part of the applied DCF enters enterohepatic circulation. The resulting prolonged availability of DCF in the organism possibly promotes accumulation of DCF, despite its basically low tendency for bioaccumulation as judged by its octanol/water partition coefficient. In other vertebrate species enterohepatic cycling has previously been associated with an increased potential for toxicity. The study at hand provides for a first indication of a similar situation in salmonids. Although this study was designed to explore metabolism and distribution of DCF in a salmonid species and did thus not a priori make use of an environmentally relevant exposure scenario, it can nevertheless indicate how exposure to environmental concentrations can give rise to adverse effects in aquatic species. It furthermore exemplifies how an environmentally persistent pharmaceutical can become even more persistent in an aquatic organism even though its $\log D$ is low.

\section{Conflict of interest statement}

The authors affiliated with Novartis (B. Hoeger and A. Hartmann) declare the following: one of Novartis' predecessor companies, CIBA-GEIGY Ltd., was the original patent holder for DCF. At present, Novartis is still marketing DCF containing medicinal products, alongside with many pharmaceutical and generic competitors. The remaining authors declare that they have no conflict of interest.

\section{Acknowledgments}

The study was supported by Grant \#BWB21002 of the Baden-Württemberg Projektträger, BWP für die Umweltforschung des Landes (BWPlus), Karlsruhe, Germany. Special thanks are due to Novartis Pharma AG for providing ${ }^{14} \mathrm{C}$-labelled DCF. The practical help of Saša Vugrinec, Annika Linke, Kerstin Stemmer, Bernhard Ernst, Dr. Stefan Hoeger, Gudrun von Scheven, Ralph Blum, Alexandra Heussner and Dr. Evelyn O'Brien as well as the permission to use a phosphor imager in Prof. Dr. Ullrich's group (University of Konstanz) is gratefully appreciated.

\section{References}

Atchison, C.R., West, A.B., Balakumaran, A., Hargus, S.J., Pohl, L.R., Daiker, D.H., Aronson, J.F., Hoffmann, W.E., Shipp, B.K., Treinen
Moslen, M., 2000. Drug enterocyte adducts: possible causal factor for diclofenac enteropathy in rats. Gastroenterology 119, 15371547.

Banks, A.T., Zimmerman, H.J., Ishak, K.G., Harter, J.G., 1995. Diclofenac associated hepatotoxicity: analysis of 180 cases reported to the food and drug administration as adverse reactions. Hepatology 22,820827 .

Barbato, F., La Rotonda, M.I., Quaglia, F., 1997. Interactions of nonsteroidal antiinflammatory drugs with phospholipids: comparison between octanol/buffer partition coefficients and chromatographic indexes on immobilized artificial membranes. J. Pharm. Sci. 86, 225229.

Beck, W.S., Schneider, H.T., Dietzel, K., Nuernberg, B., Brune, K., 1990. Gastrointestinal ulcerations induced by anti inflammatory drugs in rats. Physicochemical and biochemical factors involved. Arch. Toxicol. 64, 210217.

Boelsterli, U.A., 2003. Diclofenac induced liver injury: a paradigm of idiosyncratic drug toxicity. Toxicol. Appl. Pharm. 192, 307322.

Buser, H.R., Poiger, T., Muller, M.D., 1998. Occurrence and fate of the pharmaceutical drug diclofenac in surface waters: rapid photodegra dation in a lake. Environ. Sci. Technol. 32, 34493456.

Dietrich, D.R., Webb, S., Petry, T. (Eds.), 2004. Hot Spot Pollutants: Pharmaceuticals in the Environment. Elsevier Academic Press, Amsterdam

Dietrich, D.R., Hitzfeld, B.C., O'Brien, E., 2006. Toxicology and risk assessment of polar organic pollutans. In: Reemtsma, T. (Ed.), Organic Pollutants in the Water Cycle. Wiley VCH, Weinheim, pp. 287310

Fitzsimmons, P.N., Fernandez, J.D., Hoffman, A.D., Butterworth, B.C., Nichols, J.W., 2001. Branchial elimination of superhydrophobic organic compounds by rainbow trout (Oncorhynchus mykiss). Aquat. Toxicol. 55, 2334.

Fukuyama, T., Yamaoka, K., Ohata, Y., Nakagawa, T., 1994. A new analysis method for disposition kinetics of enterohepatic circulation of diclofenac in rats. Drug Metab. Dispos. 22, 479485.

Grillo, M.P., Hua, F., Knutson, C.G., Ware, J.A., Li, C., $2003 a$. Mechanistic studies on the bioactivation of diclofenac: identification of diclofenac $S$ acyl glutathione in vitro in incubations with rat and human hepatocytes. Chem. Res. Toxicol. 16, 14101417.

Grillo, M.P., Knutson, C.G., Sanders, P.E., Waldon, D.J., Hua, F., Ware, J.A., 2003b. Studies on the chemical reactivity of diclofenac acyl glucuronide with glutathione: identification of diclofenac $S$ acyl glutathione in rat bile. Drug Metab. Dispos. 31, 13271336

Grosser, T., Yusuff, S., Cheskis, E., Pack, M.A., FitzGerald, G.A., 2002. Developmental expression of functional cyclooxygenases in zebrafish. Proc. Natl. Acad. Sci. USA 99, 84188423.

Hargus, S.J., Amouzedeh, H.R., Pumford, N.R., Myers, T.G., McCoy, S.C., Pohl, L.R., 1994. Metabolic activation and immunochemical localization of liver protein adducts of the nonsteroidal anti inflammatory drug diclofenac. Chem. Res. Toxicol. 7, 575582.

Hargus, S.J., Martin, B.M., George, J.W., Pohl, L.R., 1995. Covalent modification of rat liver dipeptidyl peptidase IV (CD26) by the nonsteroidal anti inflammatory drug diclofenac. Chem. Res. Toxicol. 8, 993996

Hickey, E.J., Raje, R.R., Reid, V.E., Gross, S.M., Ray, S.D., 2001. Diclofenac induced in vivo nephrotoxicity may involve oxidative stress mediated massive genomic DNA fragmentation and apoptotic cell death. Free Radic. Biol. Med. 31, 139152.

Hoeger, B., Kollner, B., Dietrich, D.R., Hitzfeld, B.C., 2005. Water borne diclofenac affects kidney and gill integrity and selected immune parameters in brown trout (Salmo trutta f. fario). Aquat. Toxicol. 75, 5364.

Huggett, D.B., Cook, J.C., Ericson, J.F., Williams, R.T., 2003. A theoretical model for utilizing mammalian pharmacology and safety data to prioritize potential impacts of human pharmaceuticals to fish. Hum. Ecol. Risk Assess. 9, 17891799.

Itazawa, Y., Takeda, T., Yamamoto, K., Azuma, T., 1983. Determination of circulating blood volume in three teleosts, carp, yellowtail and porgy. Jpn. J. Ichthyol. 30, 94107. 
Kretz-Rommel, A., Boelsterli, U.A., 1994. Mechanism of covalent adduct formation of diclofenac to rat hepatic microsomal proteins. Retention of the glucuronic acid moiety in the adduct. Drug Metab. Dispos. 22, 956-961.

Oaks, J.L., Gilbert, M., Virani, M.Z., Watson, R.T., Meteyer, C.U., Rideout, B.A., Shivaprasad, H.L., Ahmed, S., Chaudhry, M.J., Arshad, M., Mahmood, S., Ali, A., Khan, A.A., 2004. Diclofenac residues as the cause of vulture population decline in Pakistan. Nature 427, 630-633.

Reuter, B.K., Davies, N.M., Wallace, J.L., 1997. Nonsteroidal antiinflammatory drug enteropathy in rats: role of permeability, bacteria, and enterohepatic circulation. Gastroenterology 112, 109-117.

Risebrough, R., 2004. Conservation biology: fatal medicine for vultures. Nature 427, 596-598.

Rowley, A.F., Knight, J., Lloyd-Evans, P., Holland, J.W., Vickers, P.J., 1995. Eicosanoids and their role in immune modulation in fish: a brief overview. Fish Shellfish Immunol. 5, 549-567.

Sanchez, S., Alarcon de la Lastra, C., Ortiz, P., Motilva, V., Martin, M.J., 2002. Gastrointestinal tolerability of metamizol, acetaminophen, and diclofenac in subchronic treatment in rats. Dig. Dis. Sci. 47, 2791-2798.

Schwaiger, J., Ferling, H., Mallow, U., Wintermayr, H., Negele, R.D., 2004. Toxic effects of the non-steroidal anti-inflammatory drug diclofenac; Part I: Histopathological alterations and bioaccumulation in rainbow trout. Aquat. Toxicol. 68, 141-150.

Seitz, S., Boelsterli, U.A., 1998. Diclofenac acyl glucuronide, a major biliary metabolite, is directly involved in small intestinal injury in rats. Gastroenterology 115, 1476-1482.

Tort, L., González-Arch, F., Torres, P., Hidalgo, J., 1991. On the blood volume of the mediterranean dogfish, Scyliorhinus canicula. Fish Physiol. Biochem. 9, 173-177.

Triebskorn, R., Casper, H., Heyd, A., Eikemper, R., Kohler, H.R., Schwaiger, J., 2004. Toxic effects of the non-steroidal anti-inflammatory drug diclofenac; Part II. Cytological effects in liver, kidney, gills and intestine of rainbow trout (Oncorhynchus mykiss). Aquat. Toxicol. 68, 151-166.

Zou, J., Hong, S., Holland, J., Stewart, I., Secombes, C.J., 2000. Differential modulation of cyclooxygenases 1 and 2 in rainbow trout. Dev. Comp. Immunol. 24, S60. 